We confess that we are unable to grasp the mentality of the General Medical Council in reference to compulsory examination in ophthalmology. The experience of many examining bodies has shown not only that it is desirable, but that it can be conducted without difficulty. We venture to hope that, failing action by the General Medical Council, universities and diploma-granting corporations may recognize the desirability, or indeed the necessity, of instituting such examinations as an integral part of their qualifying examination.

\title{
Ophthalmic Research in the Combatant Services
}

A valuable and interesting discussion on ophthalmology in its relation to the Navy, Army, and Air Force took place at the British Medical Association meeting at Portsmouth. We have already (Brit. Jl. of Ophthal., p. 448) mentioned the names of the chief speakers on behalf of the various services and in the ensuing discussion. The President of the Section, Sir John Parsons, pointed out that during the war innumerable ophthalmic problems arose in connection with all three services. In most cases the correct solution could only have been attained by prolonged research, which at that time was often impossible. Action had to be taken on data which were incomplete and faulty. In many cases, notably in the Air Force, ineffective action was attended by serious loss of life and the destruction of valuable material. So impressed were the authorities-and the same applied to the American and other governments-with the imperative need for research in these matters that exhaustive investigations were initiated and are still being carried on. The importance of similar problems arising in connection with naval and military affairs does not impress the authorities with the same dramatic intensity. Yet it is obvious that they should be attacked, and that the proper time to attack them is in peace time. Even in these exigent times money is forthcoming for Industrial and Medical Research, and experience shows that it could not be better invested. The efficiency of the combatant services is a supreme duty which no statesman should dare to neglect, but it can only be attained by constant watchfulness and enterprise, and these are liable to sink into apathy and inertia in the comparative security of peace. The meeting signified its appreciation of the validity of these arguments-so ably exemplitied in the remarks of Air-Commodore Munro, Wing-Commander Clements, Gen. Sir Wm. Macpherson, Major Gurley, and Surgeon-Commander Breton-that a resolution urging the Government to carry on research in these ocular problems was carried unanimously. 